\title{
Actinic cheilitis adjacent to squamous carcinoma of the lips as an indicator of prognosis.
}

\author{
Marilda Aparecida Milanez Morgado de Abreu ', \\ Olga Maria Panhoca da Silva ${ }^{2}$, Dalva Regina Neto \\ Pimentel ${ }^{3}$, Cleonice Hitomi Watashi Hirata ${ }^{4}$, Luc \\ Louis Maurice Weckx ${ }^{5}$, Mauricio Mota de Avelar \\ Alchorne ${ }^{6}$, Nilceo Shwery Michalany ${ }^{7}$
}

Keywords: squamous cell carcinoma, histopathological exam, lips, prognostic.

\section{Summary}

\begin{abstract}
M cheilitis and squamous carcinoma of the lips. Aim: The aim of the study was to observe the relation between actinic cheilitis and the prognosis of squamous carcinoma of the lips. Materials and Methods: This is a retrospective crosssectional cohort study of squamous carcinoma of the lips. Histological sections of squamous carcinoma tumors done at the the Departament of Pathology of the Sao Paulo Federal University between 1993 and 2000 were reviewed for evidence of actinic cheilitis in the lip vermillion adjacent to the tumor. Patient reports were reviewed to find information about exposure to sun, metastases and relapses. The occurrence or absence of relapses and metastases was correlated with the presence or absence of actinic cheilitis in the lip vermillion. Data was analyzed by Fisher's Exact test. Results: Of the 31 selected patients, most were caucasian, males and with lower lip involvement. Statistical analysis demonstrated independence between the occurrence of metastases and relapse and gender, skin color and site (lower or upper lips). There was dependence between actinic cheilitis and solar elastosis, and between the absence of actinic cheilitis and the occurrence of metastases. There was no dependence between the absence of actinic cheilitis and the occurrence of relapses. Conclusion: It may be concluded that tumors originating from actinic cheilitis have a better prognosis.
\end{abstract}

\footnotetext{
${ }^{1}$ M.S., PostGraduate Student in Stomatology - Departments of Dermatology and Otorhinolaryngology and Human Communication Disorders - Federal University of São Paulo - Paulista School of Medicine; Professor of Dermatology - Presidente Prudente Medical School, Oeste Paulista University. ${ }^{2}$ Post-Doctor in Epidemiology; PhD and M.S. in Public Health; Researcher of the Mackenzie Presbiterian University.

${ }^{3}$ M.S. , PostGraduate Student in Stomatology - Departments of Dermatology and Otorhinolaryngology and Human Communication Disorders - Federal University of São Paulo - Paulista School of Medicine.

${ }^{4}$ M.S. PhD, Head of the Stomatology Department - Departments of Dermatology and Otorhinolaryngology and Human Communication Disorders - Federal University of São Paulo - Paulista School of Medicine.

${ }^{5}$ Full Professor - Department of Pediatric Otorhinolaryngology and Human Communication Disorders; Head of the Department of Otorhinolaryngology/HNS - Federal University of São Paulo, Paulista School of Medicine.

${ }^{6}$ Associate Professor. Full Professor - Department of Dermatology - Federal University of São Paulo/Paulista School of Medicine.

${ }^{7}$ M.S. Associate Professor of Pathology - Federal University of São Paulo/Paulista School of Medicine. Federal University of São Paulo/Paulista School of Medicine (UNIFESP/EPM).

Mailing Address: Marilda Aparecida Milanez Morgado de Abreu - Rua Brasil 1599 Dracena SP 17900-000. Tel: (0xx18) 3821-4630 - Fax: (0xx18) 3821-2276 - E-mail: lfmabreu@uol.com.br

Paper submitted to the ABORL-CCF SGP (Management Publications System), on November 8th, 2005. and accepted for publication on October 21st, 2006. cod 1571.
} 


\section{INTRODUCTION}

Cancer is still a great challenge in medicine, and its etiology remains largely unknown. A population study in the city of Sao Paulo1 showed that $89.9 \%$ of mouth cancers are squamous cell carcinomas, found both in children and the elderly. The incidence of this tumor is 20.88 per 100,000 inhabitants $(33.25$ per 100,000 in men and 9.59 per 100,000 in women). Incidence on the lips is 3.2 per 100,000 inhabitants. 1 The most commonly affected site in the mouth is the lower lip $p^{2,3}$ and a higher rate is seen in whites. 4,5 When affected, young people generally have an underlying disease or immunodepression. ${ }^{6,7}$ Clinical and epidemiological evidence suggests that actinic radiation is the cause of squamous cell carcinoma on the lips. Solar elastosis and chronic actinic cheilitis seen histologically on the lip vermillion occur adjacent to the tumor in nearly every case, with evidence of a significant relation between these conditions. ${ }^{8,10}$

The behavior of lip squamous cell carcinoma does not follow the same pattern described for skin and mouth cancers. Lip malignancies are more prone to metastasize compared to skin cancers, with rates varying from $3 \%$ to $20 \%$; however, the prognosis is better compared to intraoral cancers. ${ }^{4,10,11}$

Clinically and epidemiologically, chronic actinic cheilitis and actinic keratosis may be considered analogous.10-14 Skin squamous cell carcinomas originating from actinic keratoses have a better prognosis, with a metastasizing rate of $0.5 \%$ to $3 \% .15$ Possibly a lip tumor originating from actinic cheilitis may have a better prognosis, similar to what occurs on the skin.

To test this hypothesis, we proposed a study of lip squamous cell carcinoma with the aim of ascertaining the relation between chronic actinic cheilitis and the prognosis of that malignancy.

\section{MATERIAL AND METHODS}

We conducted a retrospective cross-sectional cohort study of cases of lip squamous cell carcinoma taken from the Sao Paulo Federal University Pathology Department files between 1993 and 2000. The project was analysed and approved by the Research Ethics Committee from UNIFESP, protocol \# 1090/01.

One pathologist reviewed original patient files and exam reports and examined slides of surgical specimens of tumors under common light microscopy.

Patient gender, age, skin color, and tumor site data were collected from original histopathological exam reports for each lesion. Information on exposure to the sun, tumor recurrence, and metastasis was obtained from the medical files.

Only tumors where the histopathological slide showed tumor-free adjacent tissue to the lip vermillion sufficient for histological analysis were included. Biopsies or tumors with neoplastically compromised margins were discarded.

Histological examination was used to study the adjacent lip vermillion to carefully check the presence or absence of actinic cheilitis. The diagnostic criteria were based on published studies according to the presence or absence of specific changes ${ }^{9,12,16-20}$ shown in Figures 1, 2 and 3 and described below:

\section{Changes in the epithelium}

- Altered keratinization: thickening of the keratin layer (hyperkeratosis) with normal keratinocytes (orthokeratosis) alternating with nuclei present in cells in this layer (parakeratosis), as well as premature and individual keratinization of keratinocytes (dyskeratosis).

- A global increase in the number of keratinocytes with thickening of the epithelium (hyperplasia) or a reduction in the number of these cells with thinning of the epithelium (atrophy), and possible exulceration.

- Mild, moderate or severe dysplasia, seen as the presence of enlarged, irregular and hyperchromatic cell nuclei, with eventual atypical mitosis.

\section{Changes in the corium}

- Solar elastosis in the superficial portion of the lamina propria characterized by sunlight-cause basophilic degeneration of the collagen and elastic tissues.

- Inflammatory infiltrate, composed mostly of lymphocytes and plasmocytes.

- Vasodilatation with no endothelial cell proliferation.

We used Fisher's exact test for statistical analysis of data including the variables gender, skin color, lesion site, the presence or absence of actinic cheilitis, solar elastosis, metastasis, and recurrence.

\section{RESULTS}

We found 86 cases of squamous cell carcinoma of the lip within the study time frame. Of these, 31 cases were selected, where the files contained the required information, and where the tumor histological slides contained adjacent tumor-free tissue. There were 7 women and 24 men in this sample. Twenty-six patients were white, 4 were brown and 1 was black. Women were aged between 40 and 82 years and men were aged between 25 and 82 years. This information is shown on Table 1 .

Twenty-eight lesions were located on the lower lip, 2 lesions were located on the upper lip, and no information was given in 1 case. Twenty-two patients (71\%) reported exposure to the sun; this information was not available for other patients.

Six cases of recurrence and 8 cases of metastasis were. Statistical analysis using Fisher's exact test demons- 


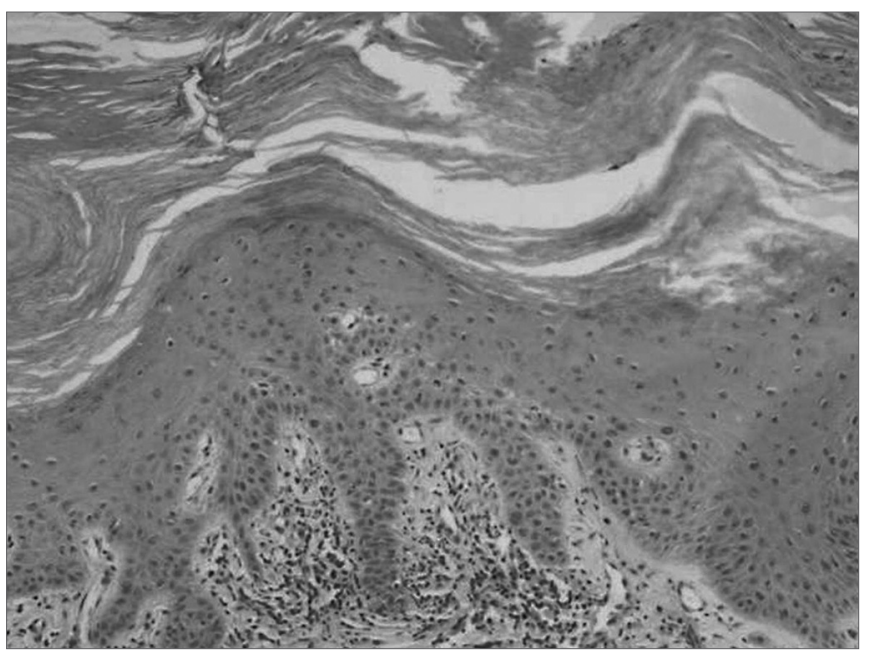

Figure 1. Epithelial hyperplasia with orthokeratosis and paraketatosis; (HE 100x)

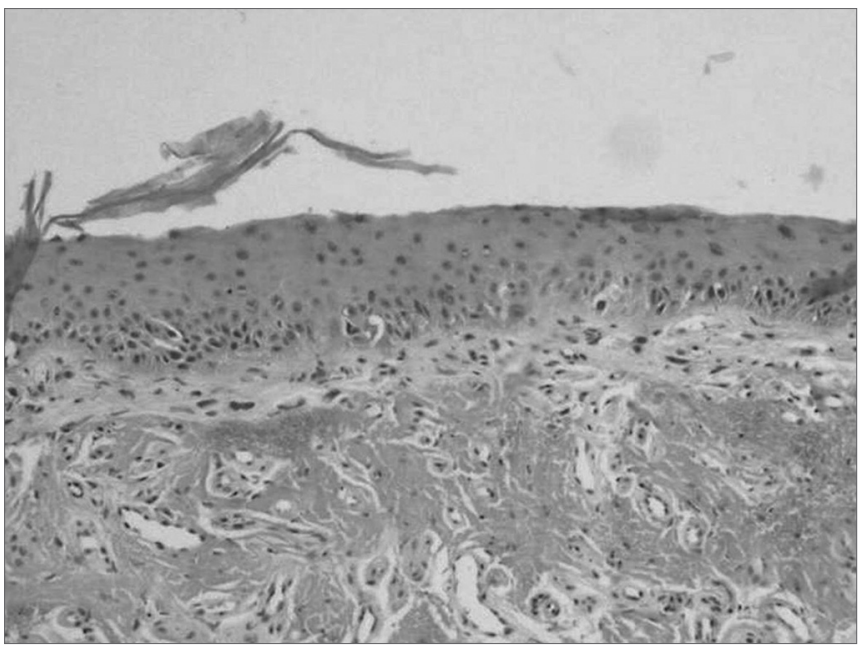

Figure 2. Epithelial atrophy, solar elastosis; (HE 10x)

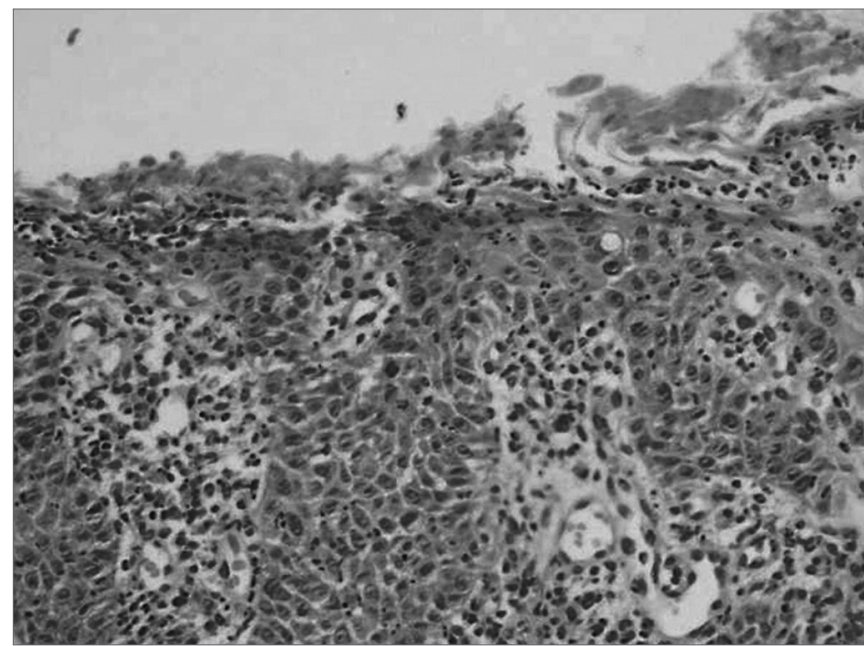

Figure 3. Epithelial exulceration; enlarged, irregular and hyperchromatic cell nuclei, with some atypical mitosis; (HE 200x)

trated that metastases and recurrences were not gender, skin color or tumor site (upper or lower lip) dependent.

Histopathology of the epithelium adjacent to the tumor revealed actinic cheilitis on the lip vermillion in 19 cases (61.3\%); of these, only 2 cases did not have solar elastosis. Isolated solar elastosis was seen in 4 cases (12.9\%). In 8 cases (25.8\%), the adjacent epithelium did not have actinic cheilitis or solar elastosis.

Statistical analysis showed that actinic cheilitis and solar elastosis were dependent (Table 2), that is, when actinic cheilitis was present, so was solar elastosis in the majority of cases.

We can see that there is a relation between the presence of actinic cheilitis and the lack of metastasis, where the former was present in lesions with no metastasis. Recurrence is independent of the presence of actinic cheilitis (Table 3).

Table 1. Distribution of lip squamous cell carcinoma cases according to age, gender and skin color. UNIFESP patients, $1993 / 2000$.

\begin{tabular}{|c|c|c|c|c|c|c|c|c|}
\hline \multirow[t]{2}{*}{ Age group } & \multicolumn{3}{|c|}{ Women } & \multicolumn{4}{|c|}{ Men } & \multirow{2}{*}{$\begin{array}{l}\text { Both sexes } \\
\text { and skin } \\
\text { color }\end{array}$} \\
\hline & White & Brown & Total & White & Black & Brown & Total & \\
\hline $20-29$ & - & - & - & 1 & - & - & 1 & 1 \\
\hline $30-39$ & - & - & - & - & - & - & - & - \\
\hline $40-49$ & 1 & - & 1 & 3 & - & - & 3 & 4 \\
\hline $60-69$ & 1 & - & 1 & 2 & - & - & 2 & 3 \\
\hline $70-79$ & 2 & 1 & 3 & 7 & 1 & 1 & 9 & 12 \\
\hline $80-89$ & 1 & - & 1 & 1 & & 2 & 3 & 4 \\
\hline Total & 6 & 1 & 7 & 20 & 1 & 3 & 24 & 31 \\
\hline
\end{tabular}


Table 2. Actinic cheilitis and solar elastosis on the lip vermillion adjacent to lip squamous cell carcinomas. UNIFESP patients, 1993/2000.

\begin{tabular}{cccc}
\hline & \multicolumn{2}{c}{ Actinic cheilitis } & Total \\
\hline Solar elastosis & No & Yes & \\
No & 8 & 2 & 10 \\
Yes & 4 & 17 & 21 \\
\hline Total & 12 & 19 & 31
\end{tabular}

Fisher's exact test, $p=0.002$

Table 3. Distribution of lip squamous cell carcinoma cases according to the presence or absence of actinic cheilitis on the lip vermillion, and recurrence and metastasis. UNIFESP patients, 1993/2000.

\begin{tabular}{ccccc}
\hline \multirow{2}{*}{$\begin{array}{c}\text { Recurren- } \\
\text { ce }\end{array}$} & No & $\begin{array}{c}\text { Tumors with no } \\
\text { actinic cheilitis }\end{array}$ & $\begin{array}{c}\text { Tumors with } \\
\text { actinic cheilitis }\end{array}$ & Total \\
\hline \multirow{7}{*}{ Metastasis } & 9 & 3 & 17 & 26 \\
& Total & 12 & 2 & 5 \\
& No & 6 & 19 & 31 \\
& Yes & 6 & 17 & 23 \\
& Total & 12 & 2 & 8 \\
\hline
\end{tabular}

Metastases were present in 25\% of cases with no actinic cheilitis, but with solar elastosis in the lip vermillion. Metastases were present $62.5 \%$ in cases with no actinic cheilitis and no solar elastosis. Recurrence was seen in $50 \%$ of cases with isolated solar elastosis, and in $12.5 \%$ of cases with no actinic cheilitis and no solar elastosis on the lip vermillion (Table 4). There was no statistical difference for recurrence and metastasis between cases with isolated solar elastosis on the lip vermillion and those cases with no solar elastosis and no actinic cheilitis.

\section{DISCUSSION}

According to medical literature, ${ }^{2,4}$ lip squamous cell carcinoma is more frequent in white men, and is usually located on the lower lip. Another finding is that men begin to present this tumor at an earlier age. The observed independence between metastasis, recurrence and tumor location on the upper or lower lip contradicts published literature,21 however, the number of upper lip lesions is too small in this study.

We may state that, according to medical literature, ${ }^{8-}$ ${ }^{10}$ solar irradiation is probably an important factor in the etiology of squamous cell carcinoma of the lips. Not only did 22 patients report exposure to the sun, but in patients where this information was not available, histology revealed solar elastosis and/or actinic cheilitis in 7 patients, changes that are demonstrably related to prolonged ex- posure to the sun.

Tumors with adjacent actinic cheilitis showed a statistically significant lower occurrence of metastasis (10.5\%) compared to tumors with no adjacent actinic cheilitis (50\%). We may thus assume that, similarly to skin tumors originating from actinic keratosis, lip tumors originating from actinic cheilitis have a better prognosis. Actinic cheilitis could, then, be considered an indicator of a more favorable progression of disease in squamous cell carcinoma of the lips, which has not been reported so far in medical literature. Recurrence was independent of the presence of actinic cheilitis, probably being related to unsuccessful treatment in cases of larger tumors, or the result of inadequate surgical treatment.

The metastasis rate of tumors with adjacent actinic cheilitis (10.5\%) is higher than the metastasis rate reported by Won-Sang et al. in $1996^{15}$ for squamous cell carcinomas of the skin originating from actinic keratosis, which was $0.5 \%$ to $3 \%$. Undoubtedly lip squamous cell carcinomas have a worse disease progression that skin squamous cell carcinomas.

One should bear in mind that in cases where actinic cheilitis adjacent to tumors was not observed, there is the possibility that previous focal actinic cheilitis was the starting point for malignancy. In these cases, tumor growth would have hidden actinic cheilitis. Moreover, the concomitant presence of solar elastosis adjacent to the tumor would be an indication of previous actinic cheilitis. Statistical analysis demonstrates a relation between actinic cheilitis and solar elastosis (Table 2). There was a lower metastasis rate in cases with no actinic cheilitis, but with solar elastosis present on the lip vermillion (25\%) compared to those cases with no actinic cheilitis and no solar elastosis (62.5\%) (Table 4).

Table 4. Distribution of lip squamous cell carcinoma cases, according to the absence of actinic cheilitis and the presence of solar elastosis, and in relation to the absence of actinic cheilitis and solar elastosis on the lip vermillion. UNIFESP patients, 1993/2000.

\begin{tabular}{ccccc}
\hline \multirow{5}{*}{ Recurrence } & Nos & $\begin{array}{c}\text { Absence of } \\
\text { actinic cheilitis } \\
\text { and presence of } \\
\text { solar elastosis }\end{array}$ & $\begin{array}{c}\text { Absence of acti- } \\
\text { nic cheilitis and } \\
\text { solar elastosis }\end{array}$ & Total \\
& No & 2 & 1 & 3 \\
& Total & 4 & 7 & 9 \\
Metastasis & Yes & 1 & 8 & 12 \\
& No & 3 & 5 & 6 \\
& Total & 4 & 3 & 6 \\
\hline
\end{tabular}


We suggest that a careful histopathological analysis of surrounding tissue be routinely made in all cases of lip tumor surgical specimens. This procedure could provide information on the progression of the tumor, guiding the surgeon as to whether further surgical procedures or closer follow-up would be appropriate.

\section{CONCLUSION}

Chronic actinic cheilitis on the tissue adjacent to lip squamous cell carcinoma may be considered an indicator of a better prognosis for these patients.

\section{REFERENCES}

1. Oliveira EF, Silva OMP, Blachman IT, Pio MRB. Perfil epidemiológico das neoplasias orais malignas no município de São Paulo, Brasil. Rev Odontol Unesp. In press 2005.

2. Antoniades DZ, Styanidis K, Papanayotou SP, Trigonidis G. Squamos cell carcinoma of the lips in a Northern Greek population. Evaluation of prognostic factors on 5-year survival rate-I. Oral Oncol, Eur J Cancer 1995;31B(5):333-9.

3. Holmkvist KA, Roenigk RK. Squamous cell carcinoma of the lip treated with Mohs micrographic surgery: outcome at 5 years. J Am Acad Dermatol 1998;38:960-6.

4. Almeida OP, Lopes MA. Prevenção das doenças bucais. In: Kriger L. Promoção de saúde bucal. São Paulo: Artes Médicas, 1997; p. 43446.

5. Antoniades DZ, Styanidis K, Papanayotou SP, Trigonidis G. Squamos cell carcinoma of the lips in a Northern Greek population. Evaluation of prognostic factors on 5-year survival rate-I. Oral Oncol, Eur J Cancer 1995;31B(5):333-9.

6. Thomas DW, Seddon SV, Shepherd JP. Systemic immunosuppression and oral malignancy: a report of a case and review of literature. $\mathrm{Br}$ J Oral Maxillofac Surg 1993;31:391-3.
7. van Zuuren EJ, Visscher JGAM, Bouwes Bavinck JN. Carcinoma of the lip in transplant recipients. J Am Acad Dermatol 1998;38:497-9.

8. Mittelbronn MA, Mullins DL, Ramos-Caro FA, Flowers FP. Frequency of pre-existing actinic keratosis in cutaneous squamous cell carcinoma. Int J Dermatol 1998;37:677-81.

9. Kaugars GE, Pillion T, Svirsky JA, Page DG, Burns JC, Abbey LM Actinic cheilitis. A review of 152 cases. Oral Surg Oral Med Oral Pathol Oral Radiol Endod 1999;88:181-6.

10. Picascia DD, Robinson JK. Actinic cheilitis: a review of the etiology, differential diagnosis and treatment. J Am Acad Dermatol 1987;17:25264 .

11. Moy RL. Clinical presentation of actinic keratoses and squamous cell carcinoma. J Am Acad Dermatol 2000;42:S8-10.

12. Cataldo E, Doku HC. Solar cheilitis. J Dermatol Surg Oncol 1981;7:98995.

13. Fitzgerald DA. Cancer precursors. Semin Cut Med Surg 1998;17(2):10813.

14. Laws RA, Wilde JL, Grabski WJ. Comparison of electrodessication with CO2 laser for the treatment of actinic cheilitis. Dermatol Surg 2000;26:349-53.

15. Won-Sang P, Hun-Kyung L, Jung-Young L, Nam-Jin Y, ChooSoung K, Sang-Ho K. P53 mutations in solar keratoses. Hum Pathol 1996;27:1180-4

16. Robinson JK. Actinic cheilits: a prospective study comparing four treatment methods. Arch Otolaryngol Head Neck Surg 1989;115:84852.

17. Pimentel DRN. Histopatologia e expressão imuno-histoquímica da proteína p53 nas quelites actínicas crônicas associada e não-associada ao carcinoma espinocelular no lábio [tese]. São Paulo: Universidade Federal de São Paulo;2003.

18. Koten JW, Verhagen ARHB, Frank GL. Histopathology of actinic cheilits. Dermatologica 1967;135:465-71.

19. Schmitt CK, Joseph S, Folsom TC. Histologic evaluation of degenerative changes of the lower lip. J Oral Surgery 1968;26:51-6.

20. Montagna W, Kirchner S, Carlisle K. Histology of sun-damage human skin. J Am Acad Dermatol 1989;21:907-18.

21. Baker SR. Malignant neoplasms of the oral cavity. In: Cummings CW, Fredrickson JM, Harker LA, Krause CJ, Schuller DE. Otolaryngology Head Neck Surg. 2nd ed. St. Louis: Mosby Year Book; 1993. p.1248305 . 